\title{
INCORPORAÇÃO DE CASCA DE ARROZ E DE BRAQUIÁRIA E SEUS EFEITOS NAS PROPRIEDADES FÍSICAS E MECÂNICAS DE TIJOLOS DE SOLO-CIMENTO
}

\author{
RÉGIS DE C. FERREIRA ${ }^{1}$, JÚLIO C. DA C. GOBO ${ }^{2}$, ANANDA H. N. CUNHA ${ }^{3}$
}

\begin{abstract}
RESUMO: A forma indiscriminada de extração dos recursos naturais e a poluição gerada pelos resíduos promovem impactos sobre o meio ambiente e é motivo de grande preocupação. Visando a oferecer alternativas de destinação de resíduos agrícolas, o presente trabalho estudou composições da mistura de solo-cimento-resíduo agrícola, tendo como objetivo principal determinar os teores máximos de resíduos a serem incorporados sem o comprometimento de suas características mecânicas. Foram utilizados dois tipos de resíduos vegetais (cascas de arroz e de braquiária) e utilizou-se o cimento Portland CP II-F-32 para a composição dos tratamentos. Nas combinações, os teores de cimento e resíduo variaram desde $100 \%$ de cimento e $0 \%$ de resíduo, até $60 \%$ de cimento e $40 \%$ de resíduo. Os tijolos foram prensados com o auxílio de máquina de fabricação de tijolos e submetidos aos ensaios de compressão simples e absorção de água. Os melhores resultados, em termos de resistência à compressão simples e de absorção de água, foram obtidos pelos tratamentos com substituição de $10 \%$ de resíduos vegetais em relação ao teor de cimento. De forma geral, os resultados sugerem a possibilidade do uso desses resíduos no teor de $10 \%$, sem o comprometimento das propriedades mecânicas relacionadas à resistência e à absorção de água dos tijolos de solocimento.
\end{abstract}

PALAVRAS-CHAVE: resíduos vegetais, tijolos de terra crua, resistência à compressão.

\section{INCORPORATION OF RICE AND BRACHIARIA HUSK AND THEIR EFFECTS ON PHYSICAL AND MECHANICAL PROPERTIES OF SOIL-CEMENT BRICKS}

\begin{abstract}
The aim of this research was to study the effect of vegetable wastes addition on physical and mechanical properties of soil-cement bricks. It was used two types of wastes (rice and Brachiaria brizantha rusk). The Portland cement content used on the soil stabilization was of $10 \%$. The combinations of cement and vegetable wastes contents varied from $100 \%$ of cement content and $0 \%$ of wastes content to $60 \%$ of cement content and $40 \%$ of waste content. The bricks were submitted to the compression tests and to the water absorption test. The best results, in terms of compression strength and water absorption capacity were reached by the $10 \%$ addition of vegetable wastes in substitution to the cement. The results suggest the promising use of these wastes, at the $10 \%$ content, without the commitment of the mechanical properties related to the resistance and to the water absorption capacity of the soil-cement bricks.
\end{abstract}

KEYWORDS: vegetable wastes, stabilized soil brick, compression strength.

\section{INTRODUÇÃO}

Já há algum tempo se faz presente, em inúmeros setores produtivos, a preocupação com a sustentabilidade, que deve envolver visão ecológica, social e econômica. O uso de tecnologias apropriadas em construções rurais ou urbanas, que levem à racionalização dos recursos disponíveis, à diminuição dos custos dos processos construtivos e ao melhor aproveitamento da mão-de-obra local deve ser, portanto, considerado (FERREIRA, 2003).

\footnotetext{
${ }^{1}$ Eng $^{\mathrm{o}}$ Agrônomo, Professor Adjunto, Setor de Engenharia Rural, Escola de Agronomia e Engenharia de Alimentos, UFG, Goiânia GO, Fone: (0XX62) 3521-1534, rcastro@agro.ufg.br

${ }^{2}$ Aluno do Curso de Agronomia, Universidade Federal de Goiás, Bolsista PIBIC/CNPq.

${ }^{3}$ Aluna do Curso de Agronomia, Universidade Federal de Goiás, Voluntária do PIVIC/CNPq.

Recebido pelo Conselho Editorial em: 30-10-2006
}

Aprovado pelo Conselho Editorial em: 15-1-2008 
A operacionalização dessas tecnologias pode ser feita por meio do uso isolado ou combinado de materiais e técnicas construtivas, convencionais ou não, tais como: terra crua, solo-cimento, argamassa armada, paredes monolíticas, elementos pré-fabricados, bambu, compósitos biomassa vegetal-cimento, etc. (FERREIRA, 2003).

A terra crua, por ser um material de grande disponibilidade e de baixo custo, vem mostrandose como excelente alternativa técnica e econômica para uso em construções rurais, por meio do resgate de técnicas, como a taipa de mão, a taipa de pilão, o adobe, as paredes monolíticas e, principalmente, sob a forma de tijolos ou blocos prensados. Seu uso isolado ou associado a aditivos químicos e/ou resíduos de atividade agrícola, industrial ou agroindustrial, tais como: cimento, cal, silicato de sódio, cinzas vegetais (da casca de arroz e do bagaço de cana-de-açúcar), cinzas volantes, escória de alto forno, dentre outros, vêm sendo objeto de inúmeras pesquisas com a finalidade de melhorar sua resistência à compressão simples, seu comportamento sob a ação da água e sua durabilidade em longo prazo (FERREIRA \& FREIRE, 2003; MESA-VALENCIANO \& FREIRE, 2004).

O cimento Portland é o estabilizador mais indicado para solos com baixos teores de argila, com os quais se obtém um material de solo-cimento de alta resistência mecânica, assim como resistência à água (baixa capacidade de absorção à água), ao inchamento e à contração. Para solos argilosos, com altos teores de limite de liquidez, a cal (hidróxido de cálcio) é o agente estabilizador mais indicado (FREIRE, 2003).

Embora quase todos os solos possam ser estabilizados com cimento, somente aqueles que necessitam de teores de cimento relativamente baixos são considerados solos economicamente empregáveis. $\mathrm{O}$ acréscimo dos teores de silte e areia, bem como a uniformidade da granulometria da areia acarretam elevação no teor de cimento (FERREIRA \& OLIVEIRA, 2006).

A estabilização do solo consiste em modificar as características do sistema solo-água-ar com a finalidade de obter propriedades de longa duração compatíveis com uma aplicação particular, ou seja, é qualquer processo, natural ou artificial, pelo qual um solo, sob o efeito de cargas aplicadas, se torna mais resistente à deformação e ao deslocamento do que o solo primitivo (HOUBEN \& GUILLAUD, 1994).

A utilização de biomassa vegetal vem apresentando grande potencial de reaproveitamento na área da construção civil, requerendo avaliação não só nos aspectos econômicos como nos aspectos tecnológicos (resistência mecânica, módulo de elasticidade, afinidade com os aglomerantes minerais, estabilidade química e geométrica, durabilidade e destino final do produto) (MILANI \& FREIRE, 2006).

O uso da casca de arroz tem sido, recentemente, objeto de diversas pesquisas com o intuito de melhorar as características físico-mecânicas de argamassas e/ou de materiais de construção baseados em terra crua (AKASAKI \& SILVA, 2001). De acordo com BERALDO \& TOJAL (2002), a grande vantagem do uso da casca de arroz como agregado alternativo reside no fato de que sua geração é concentrada em poucos locais, o que facilita a sua comercialização. Além disso, a granulometria do material é relativamente uniforme, o que facilita a dosagem do compósito. Situação semelhante ocorre com os resíduos oriundos das usinas de beneficiamento de sementes de forrageiras, como as do capim braquiária (Brachiaria brizantha). A casca que envolve a semente é, na maioria das vezes, descartada, pela inexistência de aproveitamento mais adequado.

Recentemente, MILANI \& FREIRE (2006) estudaram os efeitos da adição da casca de arroz nas propriedades físico-mecânicas (capacidade de absorção de água e resistências à compressão simples e diametral) da mistura de solo-cimento, visando a obter composições de solo-cimentocasca de arroz com potencialidade para fabricação de materiais alternativos de construção. As composições solo-cimento-casca de arroz foram submetidas aos ensaios de compressão simples, aos 7; 28 e 56 dias, e de absorção de água, aos 7 dias. Após a determinação das características físicas e mecânicas estudadas, os autores concluíram que misturas de solo associado ao teor de $12 \%$ de 
combinações de cimento e casca de arroz se mostraram promissores como materiais para posterior utilização na fabricação de elementos construtivos em construções e instalações rurais.

Diante desse contexto, a presente pesquisa torna-se de grande importância para a obtenção de novos produtos que acompanhem o processo tecnológico e minimizem a degradação ambiental. Pretende-se, com este trabalho, estudar a otimização do uso de resíduos vegetais in natura na fabricação de tijolos de terra crua estabilizados com cimento.

\section{MATERIAL E MÉTODOS}

Foram utilizados solos e resíduos vegetais previamente caracterizados por FERREIRA \& OLIVEIRA (2006) (Tabelas 1 e 2, respectivamente). O solo utilizado foi retirado de uma jazida localizada na região nordeste do município de Goiânia, no Residencial Nossa Morada, em setembro de 2004. A princípio, o solo mostrou-se impróprio para seu uso em misturas de solo-cimento, apresentando os valores dos limites de consistência e de teor máximo de argila em desacordo com aqueles recomendados pela NBR 10832 (ABNT, 1989). Dessa maneira, foi realizada correção granulométrica do solo mediante a adição de areia a fim de adequá-lo às recomendações da ABNT, ou seja, $100 \%$ dos grãos passando na peneira ABNT 4,8 mm (n- 04), 10\% a 50\% dos grãos passando na peneira ABNT $0,075 \mathrm{~mm}\left(\mathrm{n}^{\mathrm{o}}\right.$ 200), limite de liquidez $\leq 45 \%$ e índice de plasticidade $\leq 18 \%$.

Os resíduos vegetais, cascas de arroz e da semente de braquiária, ambos in natura, foram obtidos em usinas de beneficiamento de arroz e forrageiras, respectivamente. Foi utilizado o cimento Portland CP II-F-32 (NBR 11578, conforme ABNT, 1991) para a composição dos tratamentos.

Para os ensaios de compressão simples dos tijolos, foi utilizada uma máquina universal de ensaios (prensa hidráulica) marca DYNATEST, com dispositivo de controle de velocidade de carregamento e capacidade de $2.500 \mathrm{kN}$ (Figura 1). Os tijolos foram moldados com o auxílio de máquina de fabricação de tijolos da marca TECMOR, de acionamento manual, para compactação da mistura fresca (Figura 2). Essa máquina, usualmente utilizada na confecção de tijolos de solocimento, tem capacidade de fabricação de três tijolos por prensagem, tijolos tipo II $\left(23 \times 11 \times 5 \mathrm{~cm}^{3}\right)$, de acordo com a NBR 8491 (ABNT, 1992a).

TABELA 1. Propriedades físicas do solo estudado. Physical properties of the studied soil.

\begin{tabular}{|c|c|c|}
\hline Índices Físicos & Solo Natural & Solo Corrigido \\
\hline Umidade natural (\%) & 14,88 & 1,36 \\
\hline Massa específica dos sólidos $\left(\mathrm{g} \mathrm{cm}^{-3}\right)$ & 3,38 & 2,72 \\
\hline Limite de liquidez $(\%)$ & 41,70 & 21,10 \\
\hline Limite de plasticidade $(\%)$ & 28,00 & 16,30 \\
\hline Índice de plasticidade $(\%)$ & 13,70 & 4,80 \\
\hline \multicolumn{3}{|c|}{ Distribuição Granulométrica (\%) } \\
\hline$\overline{\text { Pedregulho }(>2 \mathrm{~mm})}$ & 0,45 & 0,14 \\
\hline Areia $(0,05-2 \mathrm{~mm})$ & 31,49 & 55,68 \\
\hline Silte $(0,005-0,05 \mathrm{~mm})$ & 5,87 & 21,21 \\
\hline Argila $(<0,005 \mathrm{~mm})$ & 62,19 & 22,97 \\
\hline Percentagem que passa na peneira $200(0,074 \mathrm{~mm})$ & 68,06 & 44,18 \\
\hline \multicolumn{3}{|c|}{ Descrição Visual do Solo } \\
\hline Classificação AASHTO & $\mathrm{A}_{7}$ & $\mathrm{~A}_{4}$ \\
\hline
\end{tabular}

Fonte: FERREIRA \& OLIVEIRA (2006) 
TABELA 2. Distribuição granulométrica dos resíduos vegetais (casca de arroz e casca de braquiária). Size distribution of the vegetable wastes (rice and brachiaria husks).

\begin{tabular}{|c|c|c|c|c|c|}
\hline \multicolumn{6}{|c|}{ Casca de Arroz } \\
\hline \multicolumn{3}{|c|}{ Natural } & \multicolumn{3}{|c|}{ Triturada e Tratada } \\
\hline Abertura da Malha (mm) & \% Retida & $\%$ Acumulada & Abertura da Malha (mm) & $\%$ Retida & $\%$ Acumulada \\
\hline $4,76(\# 4)^{1}$ & 0,11 & 0,11 & $4,76(\# 4)$ & 0,00 & 0,00 \\
\hline $2,00(\# 10)$ & 41,17 & 41,28 & $2,00(\# 10)$ & 0,51 & 0,51 \\
\hline $1,19(\# 16)$ & 48,70 & 89,98 & $1,19(\# 16)$ & 17,28 & 17,79 \\
\hline $0,59(\# 30)$ & 8,74 & 98,72 & $0,59(\# 30)$ & 62,17 & 79,96 \\
\hline $0,42(\# 40)$ & 0,57 & 99,29 & $0,42(\# 40)$ & 11,14 & 91,10 \\
\hline Fundo & 0,71 & 100,00 & Fundo & 8,90 & 100,00 \\
\hline \multicolumn{6}{|c|}{ Casca de Braquiária } \\
\hline \multicolumn{3}{|c|}{ Natural } & \multicolumn{3}{|c|}{ Triturada e Tratada } \\
\hline Abertura da Malha (mm) & $\%$ Retida & $\%$ Acumulada & Abertura da Malha (mm) & $\%$ Retida & $\%$ Acumulada \\
\hline $4,76(\# 4)^{1}$ & 0,05 & 0,05 & $4,76(\# 4)$ & 0,00 & 0,00 \\
\hline $2,00(\# 10)$ & 76,09 & 76,14 & $2,38(\# 8)$ & 27,31 & 27,31 \\
\hline $1,19(\# 16)$ & 15,35 & 91,49 & $1,19(\# 16)$ & 32,34 & 59,65 \\
\hline 0,59 (\# 30) & 6,76 & 98,25 & $0,59(\# 30)$ & 23,41 & 83,06 \\
\hline $0,42(\# 40)$ & 0,95 & 99,20 & $0,42(\# 40)$ & 8,42 & 91,48 \\
\hline Fundo & 0,80 & 100,00 & Fundo & 8,52 & 100,00 \\
\hline
\end{tabular}

${ }^{1}$ Valores em parênteses referem-se à numeração das peneiras, de acordo com a NBR 7181 (ABNT, 1984a).

Fonte: FERREIRA \& OLIVEIRA (2006)

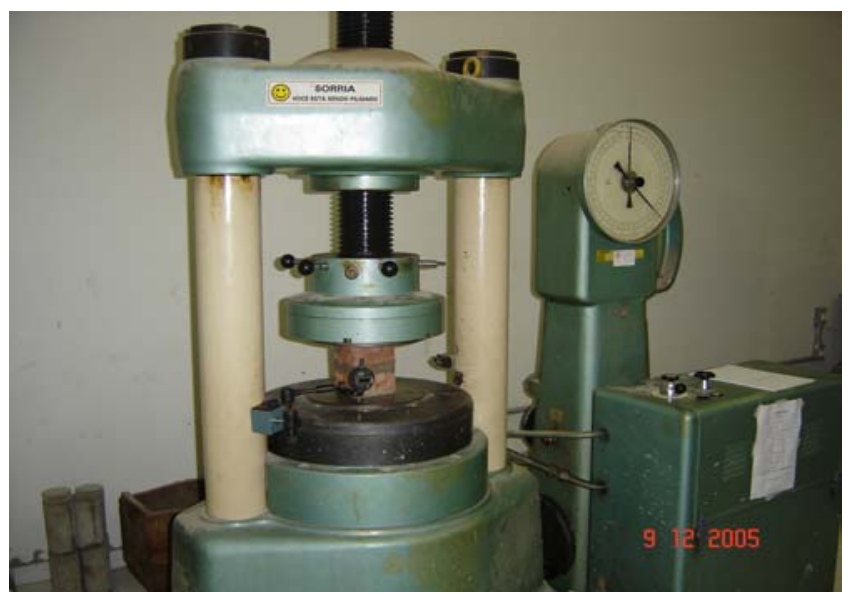

FIGURA 1. Máquina universal de ensaios (DYNATEST). Essay Universal Machine (DYNATEST).

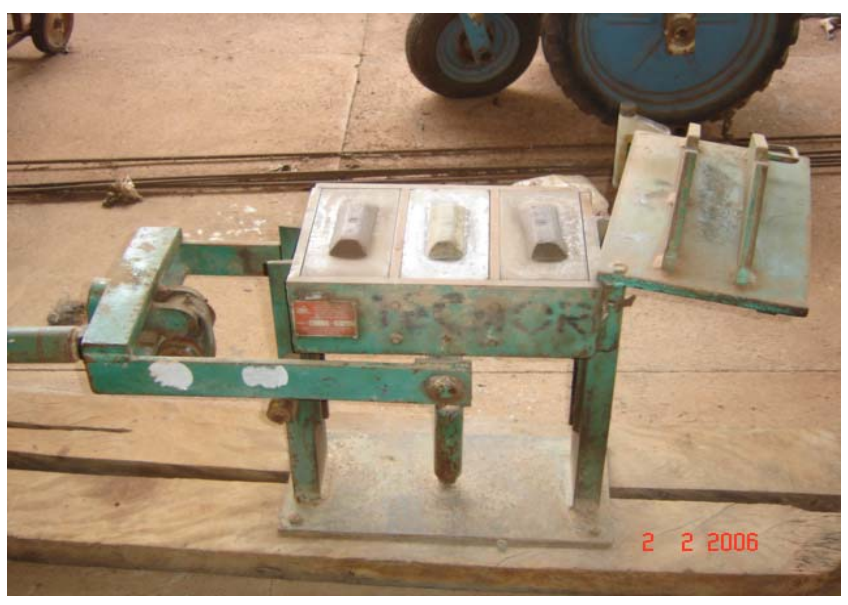

FIGURA 2. Máquina de fabricação de tijolos da marca TECMOR. Manually operated brick making machine (TECMOR).

De acordo com FERREIRA \& OLIVEIRA (2006), os resíduos vegetais foram triturados em moinho de martelo e peneirados (utilizando a fração das cascas compreendida entre 4,8 mm e 0,42 $\mathrm{mm}$ de aberturas de malha), eliminando-se a fração fina, promovendo-se a uniformização e a melhoria da adesão das cascas ao sistema solo-cimento.

A casca de arroz, em sua condição natural, caracterizou-se como sendo um material leve, com massa unitária de $0,086 \mathrm{~g} \mathrm{~cm}^{-3}$ e de granulometria uniforme (89\% compreendido entre as peneiras de 2,00 $\mathrm{mm}$ e $1,19 \mathrm{~mm}$ ). Por outro lado, depois de passar pelos processos de fracionamento, peneiramento e pré-tratamento, a massa unitária da casca de arroz aumentou para $0,152 \mathrm{~g} \mathrm{~cm}^{-3}$. Cerca de $90 \%$ da sua massa apresentou-se com diâmetro variando de $1,19 \mathrm{~mm}$ a $0,42 \mathrm{~mm}$. Por sua vez, a casca da semente de braquiária, em sua condição natural, caracterizou-se como sendo um material leve, com massa unitária de $0,059 \mathrm{~g} \mathrm{~cm}^{-3}$ e de granulometria uniforme $(91 \%$ compreendido entre as peneiras de 2,00 $\mathrm{mm}$ e $1,19 \mathrm{~mm}$ ). Após passar pelos processos de fracionamento, 
peneiramento e pré-tratamento, a massa unitária aumentou para $0,096 \mathrm{~g} \mathrm{~cm}^{-3}$, e $83 \%$ da sua massa apresentou-se com diâmetro variando de $2,00 \mathrm{~mm}$ a $0,105 \mathrm{~mm}$.

Após a trituração e o peneiramento, os resíduos foram imersos em solução de cal hidratada comum CH III, da marca Supercal, concentrada a 5\%, por um período de 24 horas, e secados em estufa por um período de 48 horas, à temperatura de $80{ }^{\circ} \mathrm{C}$, de acordo com as recomendações de MILANI \& FREIRE (2006). De acordo com esses autores, tal procedimento foi necessário para evitar a incompatibilidade química entre a biomassa vegetal e o aglomerante mineral.

Com o objetivo de adicionar a máxima quantidade de resíduo e diminuir o consumo de cimento na mistura solo-cimento-resíduo, foi adotado o teor de $10 \%$ da combinação de cimento e resíduo (\% em relação à massa do solo seco). Em seguida, foram adotados os procedimentos realizados por MILANI \& FREIRE (2006), em que, nas combinações (tratamentos), os teores de cimento e de resíduo variaram desde $100 \%$ de aglomerante e $0 \%$ de casca, até $60 \%$ de aglomerante e $40 \%$ de casca em incrementos de 10\%. Percentagens maiores de casca de resíduo afetaram negativamente a trabalhabilidade e a compactação da mistura.

Na Tabela 3, apresentam-se os valores da massa específica aparente seca máxima e da umidade ótima de compactação das composições solo-cimento-resíduo, obtidos pelos ensaios de compactação Proctor normal realizados previamente por FERREIRA \& OLIVEIRA (2006).

TABELA 3. Massa específica aparente seca máxima $\left(\gamma_{\text {máx }}\right.$ em $\left.\mathrm{g} \mathrm{cm}^{-3}\right)$ e umidade ótima de compactação $\left(\mathrm{U}_{\mathrm{ot}}, \mathrm{em} \%\right)$ das composições solo-cimento-resíduo, obtidas pelo ensaio de compactação de Proctor normal. Maximum bulk dry density $\left(\mathbf{g ~ c m}^{-3}\right)$ and optimum moisture content (\%) of soil mixtures obtained by the Normal Proctor Essay.

\begin{tabular}{lcc}
\hline Tratamentos (solo-cimento-resíduo) & $\gamma_{\text {máx }}\left(\mathrm{g} \mathrm{cm}^{-3}\right)$ & $\mathrm{U}_{\text {ot }}(\%)$ \\
\hline $\mathrm{T}_{1}-10 \%$ de adições $(0 \%$ de resíduo $+100 \%$ de cimento) & 1,82 & 16,72 \\
$\mathrm{~T}_{2}-10 \%$ de adições $(10 \%$ de casca arroz $+90 \%$ de cimento) & 1,77 & 17,72 \\
$\mathrm{~T}_{3}-10 \%$ de adições $(20 \%$ de casca arroz $+80 \%$ de cimento) & 1,73 & 18,64 \\
$\mathrm{~T}_{4}-10 \%$ de adições $(30 \%$ de casca arroz $+70 \%$ de cimento) & 1,73 & 18,25 \\
$\mathrm{~T}_{5}-10 \%$ de adições $(40 \%$ de casca arroz $+60 \%$ de cimento) & 1,68 & 19,31 \\
$\mathrm{~T}_{6}-10 \%$ de adições $(10 \%$ de casca braquiária $+90 \%$ de cimento) & 1,79 & 16,94 \\
$\mathrm{~T}_{7}-10 \%$ de adições $(20 \%$ de casca braquiária $+80 \%$ de cimento) & 1,73 & 18,56 \\
$\mathrm{~T}_{8}-10 \%$ de adições $(30 \%$ de casca braquiária $+70 \%$ de cimento) & 1,72 & 19,05 \\
$\mathrm{~T}_{9}-10 \%$ de adições $(40 \%$ de casca braquiária $+60 \%$ de cimento) & 1,70 & 19,91 \\
\hline
\end{tabular}

Fonte: FERREIRA \& OLIVEIRA (2006).

Os tijolos referentes a cada tratamento de solo-cimento-resíduo foram moldados de acordo com a NBR 10832 (ABNT, 1989). Uma vez preparada a mistura de solo-aditivo, os tijolos foram moldados no teor de água ótimo de compactação normal de Proctor (Tabela 3), adicionando-se, aos poucos, a água de amassamento até obter uniformidade de mistura para colocação nas fôrmas. Para garantir que os tijolos fossem submetidos à pressão de compactação semelhante à do Proctor normal, procedeu-se ao controle da prensagem dos tijolos relacionando-se a massa do tijolo com a massa do corpo-de-prova, admitindo-se que ambos tivessem a mesma massa específica aparente seca máxima e a mesma umidade ótima.

Após a prensagem, os tijolos foram levados à câmara úmida para cura durante o período de 7 dias, após os quais foram armazenados à sombra e protegidos das intempéries climáticas até os 182 dias de idade. Aos 7; 28; 56; 91 e 182 dias após a moldagem, os tijolos foram rompidos à compressão simples, conforme a NBR 8492 (ABNT, 1992b). A resistência à compressão simples foi calculada individualmente para cada tijolo, dividindo-se a carga de ruptura pela área da seção transversal do mesmo. A resistência média foi determinada pela média aritmética de três repetições. 
Durante os ensaios de compressão simples, foram também registrados os valores de deformação dos tijolos por meio de relógio comparador digital da marca MITUTOYO acoplado à prensa hidráulica (Figura 3). Posteriormente, os diagramas tensão-deformação para as diferentes idades e tipos de resíduos foram elaborados a partir da média aritmética das três repetições dos valores de tensão e de deformação registrados para cada tratamento durante o ensaio de compressão simples para cada tratamento.

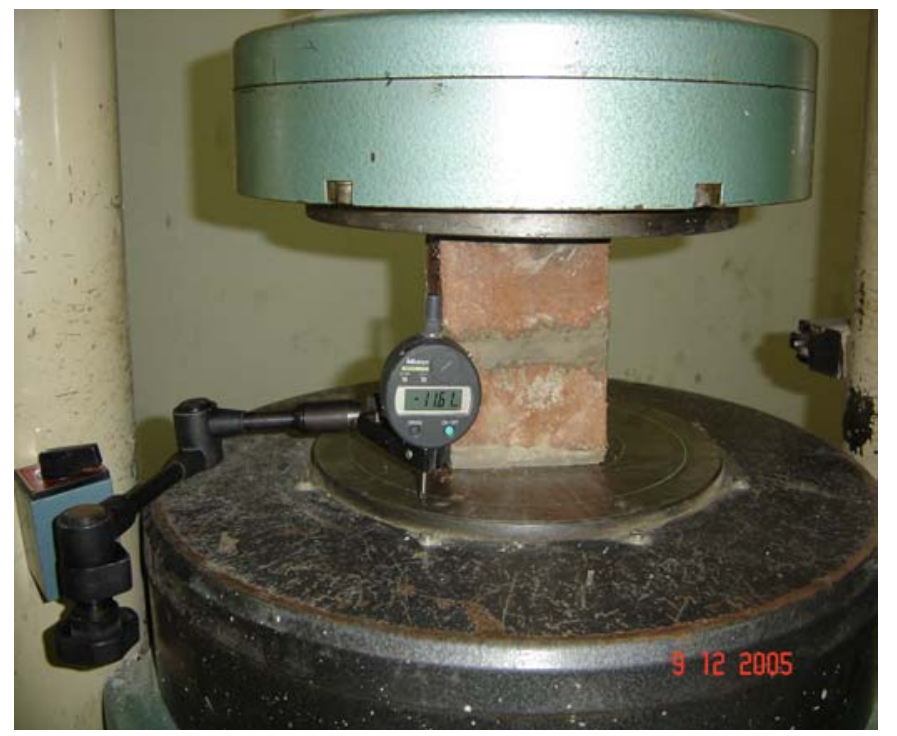

FIGURA 3. Detalhe do relógio comparador digital acoplado à prensa hidráulica. Digital indicator (MITUTOYO) coupled to the essay machine.

O ensaio de absorção de água dos tijolos foi realizado para cada tratamento, de acordo com os procedimentos da NBR 8492 (ABNT, 1984b), somente para a idade de 7 dias. Os tijolos foram levados à estufa, entre $105{ }^{\circ} \mathrm{C}$ e $110{ }^{\circ} \mathrm{C}$, até constância de massa, obtendo-se, assim, a massa do tijolo seco em estufa. Em seguida, os tijolos foram imersos em água durante $24 \mathrm{~h}$. Após esse período, os tijolos foram retirados, enxugados superficialmente e novamente pesados, anotando-se sua massa saturada. A diferença percentual entre a massa saturada e a massa úmida do tijolo correspondeu ao valor de sua capacidade parcial de absorção de água; já a diferença percentual entre a massa saturada e a massa seca correspondeu ao valor de sua capacidade total de absorção de água. Os valores individuais de absorção total de água, expressos em percentagem, foram obtidos pela seguinte equação:

$$
\mathrm{A}=\frac{\mathrm{M}_{2}-\mathrm{M}_{1}}{\mathrm{M}_{1}} 100
$$

em que,

$\mathrm{M}_{1}$ - massa do tijolo seco em estufa, g;

$\mathrm{M}_{2}$ - massa do tijolo saturado, $\mathrm{g}, \mathrm{e}$

A - absorção total de água, \%.

O plano experimental correspondeu ao esquema fatorial $2 \times 5 \times 5$, delineado inteiramente casualizado, com três repetições. Os fatores de variação foram os tipos de resíduos, em dois níveis (cascas de arroz e de braquiária), os teores de resíduo, em cinco níveis $(0 ; 10 ; 20 ; 30$ e 40\%), e as idades dos tijolos, em cinco níveis $(7 ; 28 ; 56 ; 91$ e 182 dias). Realizou-se análise de variância para avaliar o efeito das interações entre os fatores sobre as variáveis-resposta resistência à compressão simples e capacidade de absorção total de água. Os ensaios físico-mecânicos de compressão simples e absorção de água foram realizados mediante três repetições para cada composição solo-cimentoresíduo e período de cura. As médias obtidas foram comparadas pelo teste Tukey, a $1 \%$ de probabilidade. 


\section{RESULTADOS E DISCUSSÃO}

$\mathrm{Na}$ Tabela 4, apresentam-se os valores médios de resistência à compressão simples e capacidade de absorção de água dos tijolos de solo-cimento-resíduos vegetais. Nas Figuras 4 e 5 , estão mostrados os valores de absorção de água e de resistência à compressão simples, aos 7 dias, respectivamente, e respectivos valores de massa específica aparente dos tijolos de solo-cimentoresíduos vegetais.

A NBR 8491 estabelece que a quantidade de cimento a ser utilizada para a fabricação de tijolos de solo-cimento, será aquela que conferir resistência à compressão simples mínima de 2,0 MPa e capacidade de absorção de água máxima de 20\%, ambos aos 7 dias de idade. Entretanto, para tijolos ou blocos não-normalizados pela $\mathrm{ABNT}$, como é o caso do material em estudo (tijolos de solo-cimento adicionados de resíduos vegetais), a NBR 8491 estabelece para a resistência à compressão o valor mínimo de 1,5 MPa. Assim, valores entre 1,5 e 2,0 MPa também foram aceitos.

Como era de se esperar, à medida que se aumentou o teor de resíduo vegetal, os valores de resistência à compressão simples diminuíram significativamente (Tabela 4 e Figura 5). Verifica-se que, independentemente da idade e do tipo de resíduo (casca de arroz e de braquiária), os melhores resultados em termos de desempenho mecânico foram alcançados pelos tratamentos $T_{2}$ e $T_{6}$. Adotando-se 1,5 $\mathrm{MPa}$ como valor mínimo de resistência à compressão simples aos 7 dias, a substituição parcial do teor de cimento por resíduo poderá ser realizada nos tratamentos $\mathrm{T}_{2}$ e $\mathrm{T}_{6}$ ( $10 \%$ casca de arroz e braquiária, respectivamente). O maior valor de resistência encontrado foi de 4,96 MPa, aos 182 dias de cura, enquanto o menor valor encontrado foi de 0,62 MPa, aos 7 dias de cura.

TABELA 4. Resistência à compressão simples (MPa) e capacidade de absorção total de água (\%) dos tijolos moldados para as misturas de solo-cimento-resíduos vegetais. Compressive strength (MPa) and water absorption (\%) of the different soil-cement bricks with vegetable wastes.

\begin{tabular}{ccccccc}
\hline \multirow{2}{*}{ Tratamentos } & \multicolumn{5}{c}{ Resistência à Compressão Simples (MPa) } & $\begin{array}{c}\text { Absorção Total de } \\
\text { Água (\%) }\end{array}$ \\
\cline { 2 - 7 } & 7 dias & 28 dias & 56 dias & 91 dias & 182 dias & 7 dias \\
\cline { 2 - 7 } & $3,00 \pm 0,27$ & $3,07 \pm 0,05$ & $4,80 \pm 0,52$ & $3,83 \pm 0,09$ & $4,96 \pm 0,35$ & $11,42 \pm 3,41$ \\
\multirow{2}{*}{$\mathrm{T}_{1}$} & $(9,08) \mathrm{aC}$ & $(1,68) \mathrm{aC}$ & $(10,88) \mathrm{aA}$ & $(2,23) \mathrm{aB}$ & $(7,10) \mathrm{aA}$ & $(29,90) \mathrm{a}$ \\
& $1,82 \pm 0,09$ & $2,25 \pm 0,05$ & $2,89 \pm 0,16$ & $2,52 \pm 0,05$ & $2,74 \pm 0,10$ & $12,97 \pm 3,06$ \\
\multirow{2}{*}{$\mathrm{T}_{2}$} & $(4,91) \mathrm{bC}$ & $(2,30) \mathrm{bB}$ & $(5,59) \mathrm{bA}$ & $(1,96) \mathrm{bB}$ & $(3,55) \mathrm{bA}$ & $(23,59) \mathrm{ab}$ \\
\hline \multirow{2}{*}{$\mathrm{T}_{3}$} & $1,34 \pm 0,05$ & $1,52 \pm 0,04$ & $2,21 \pm 0,06$ & $1,77 \pm 0,07$ & $2,40 \pm 0,13$ & $13,78 \pm 3,75$ \\
& $(3,86) \mathrm{cC}$ & $(2,57) \mathrm{cBC}$ & $(2,92) \mathrm{cA}$ & $(3,81) \mathrm{cB}$ & $(5,63) \mathrm{cA}$ & $(27,20) \mathrm{ab}$ \\
\hline \multirow{2}{*}{$\mathrm{T}_{4}$} & $1,07 \pm 0,07$ & $1,21 \pm 0,04$ & $1,40 \pm 0,18$ & $1,54 \pm 0,03$ & $1,75 \pm 0,05$ & $16,42 \pm 5,79$ \\
& $(6,28) \mathrm{cdC}$ & $(3,21) \mathrm{cdBC}$ & $(12,73) \mathrm{dB}$ & $(2,09) \mathrm{cA}$ & $(2,95) \mathrm{dA}$ & $(35,27) \mathrm{ab}$ \\
\hline \multirow{2}{*}{$\mathrm{T}_{5}$} & $0,98 \pm 0,02$ & $1,03 \pm 0,00$ & $1,00 \pm 0,13$ & $1,15 \pm 0,03$ & $1,63 \pm 0,04$ & $18,51 \pm 4,97$ \\
& $(1,99) \mathrm{dB}$ & $(0,00) \mathrm{dB}$ & $(13,42) \mathrm{eB}$ & $(2,82) \mathrm{deB}$ & $(2,40) \mathrm{dA}$ & $(26,88) \mathrm{ab}$ \\
\hline \multirow{2}{*}{$\mathrm{T}_{6}$} & $1,53 \pm 0,15$ & $2,16 \pm 0,07$ & $2,61 \pm 0,28$ & $2,35 \pm 0,11$ & $2,99 \pm 0,12$ & $12,33 \pm 2,80$ \\
& $(10,11) \mathrm{bD}$ & $(3,25) \mathrm{bC}$ & $(10,78) \mathrm{bB}$ & $(4,83) \mathrm{bBC}$ & $(3,96) \mathrm{bA}$ & $(22,75) \mathrm{a}$ \\
\hline \multirow{2}{*}{$\mathrm{T}_{7}$} & $1,07 \pm 0,07$ & $1,17 \pm 0,05$ & $1,58 \pm 0,06$ & $1,33 \pm 0,05$ & $1,75 \pm 0,07$ & $12,71 \pm 1,46$ \\
& $(6,28) \mathrm{cdB}$ & $(4,40) \mathrm{dB}$ & $(4,08) \mathrm{dA}$ & $(3,70) \mathrm{dB}$ & $(4,01) \mathrm{dA}$ & $(11,50) \mathrm{ab}$ \\
\hline \multirow{2}{*}{$\mathrm{T}_{8}$} & $0,83 \pm 0,07$ & $0,91 \pm 0,03$ & $0,91 \pm 0,12$ & $1,16 \pm 0,07$ & $1,29 \pm 0,07$ & $15,14 \pm 4,51$ \\
& $(8,16) \mathrm{deB}$ & $(3,71) \mathrm{deB}$ & $(12,80) \mathrm{eB}$ & $(5,79) \mathrm{deA}$ & $(5,42) \mathrm{eA}$ & $(29,79) \mathrm{ab}$ \\
\hline \multirow{2}{*}{$\mathrm{T}_{9}$} & $0,62 \pm 0,03$ & $0,69 \pm 0,07$ & $1,00 \pm 0,15$ & $1,01 \pm 0,07$ & $0,69 \pm 0,04$ & $19,96 \pm 7,47$ \\
& $(5,44) \mathrm{eB}$ & $(10,20) \mathrm{eB}$ & $(15,23) \mathrm{eA}$ & $(6,62) \mathrm{eA}$ & $(5,66) \mathrm{fB}$ & $(37,42) \mathrm{b}$ \\
\hline
\end{tabular}

${ }^{1}$ Valores médios \pm desvio-padrão (coeficiente de variação, em \%). Em cada coluna, médias seguidas de mesma letra minúscula não diferem entre si, pelo teste de Tukey, a 1\% de probabilidade. Em cada linha, médias seguidas de mesma letra maiúscula não diferem entre si, pelo teste de Tukey, a $1 \%$ de probabilidade. 
Comparando-se os resíduos, a adição da casca de arroz proporcionou valores de resistência à compressão simples mais elevados do que aqueles proporcionados pela casca de braquiária, nos teores correspondentes, em todas as idades de cura. Para 7 dias, a resistência com a utilização da casca de arroz foi cerca de $19 ; 25 ; 29$ e $58 \%$ superiores às obtidas com a casca de braquiária, respectivamente, para os teores de $10 ; 20 ; 30$ e $40 \%$ de casca.

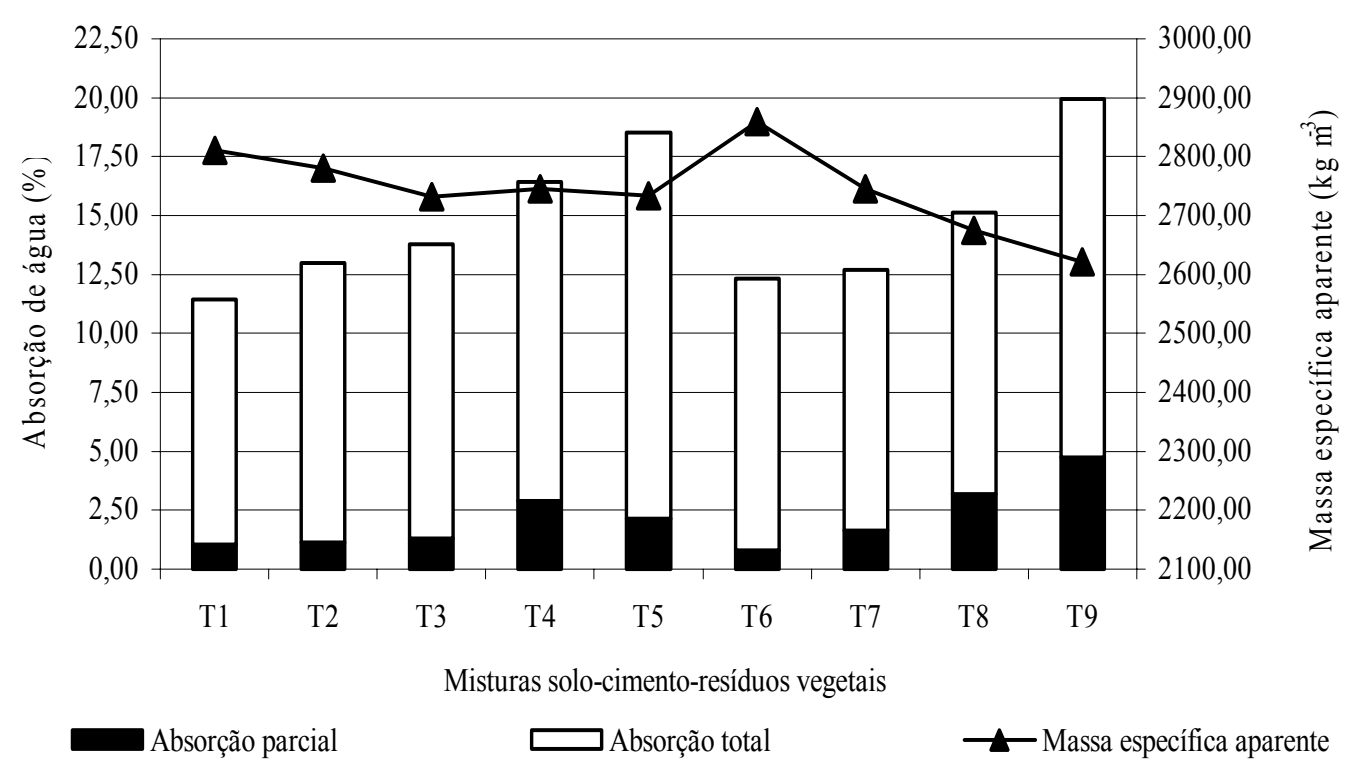

FIGURA 4. Absorção de água (\%) e massa específica aparente $\left(\mathrm{kg} \mathrm{m}^{-3}\right)$ dos tijolos de solo-cimentoresíduos vegetais. Water absorption $(\%)$ and bulk density $\left(\mathrm{kg} \mathrm{m}^{-3}\right)$ values of the soil-cement bricks with vegetable wastes.

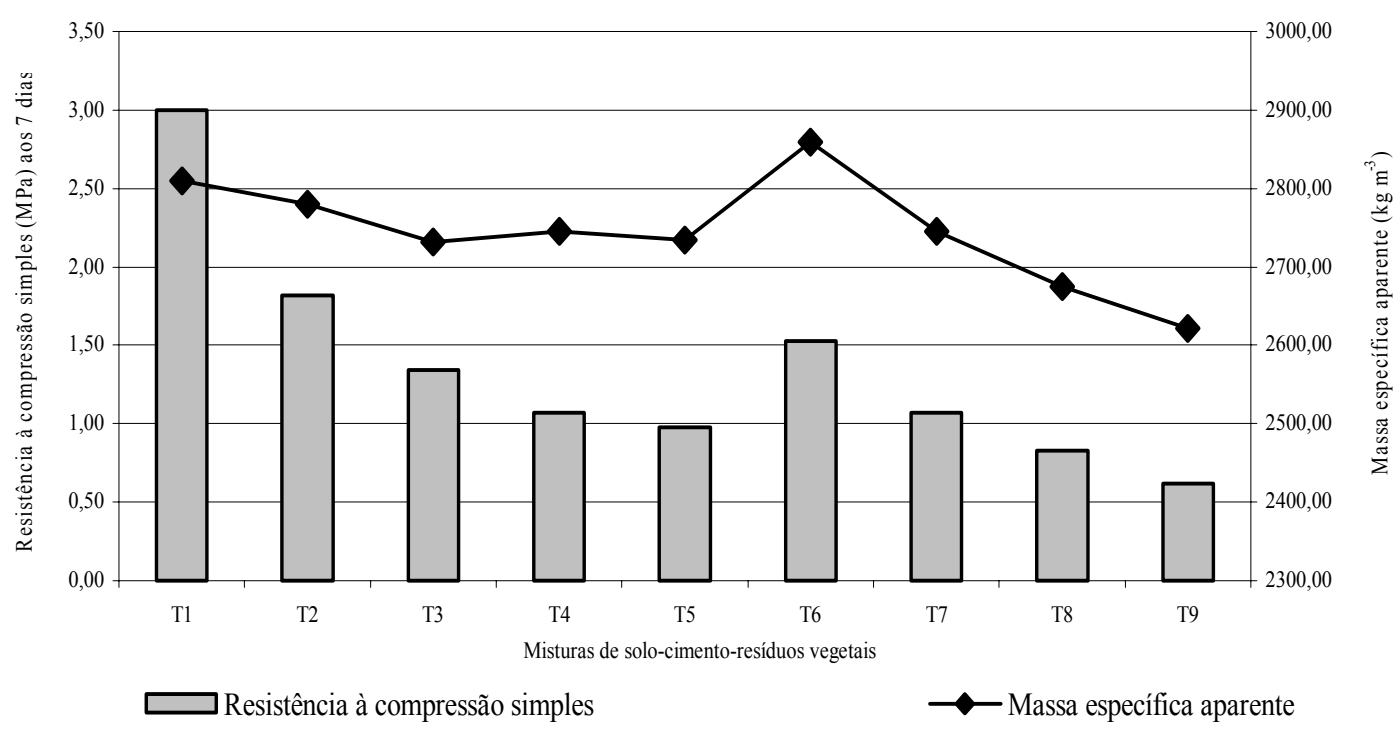

FIGURA 5. Resistência à compressão simples $(\mathrm{MPa})$ e massa específica aparente $\left(\mathrm{kg} \mathrm{m}^{-3}\right)$ dos tijolos de solo-cimento-resíduos vegetais aos 7 dias. Compressive strength (MPa) and bulk density $\left(\mathrm{kg} \mathrm{m}^{-3}\right)$ values of the soil-cement bricks with vegetable wastes.

Comparando-se os períodos de cura dos tijolos $(7 ; 28 ; 56 ; 91$ e 182 dias), houve ganho significativo da resistência, exceto pelos tratamentos $T_{1}, T_{2}, T_{3}, T_{6}$ e $T_{7}$, na idade de 91 dias, e $T_{2}$ e $\mathrm{T}_{9}$ para a idade de 182 dias. Esses tratamentos apresentaram valores de resistência menores que aqueles observados na idade de 56 dias. $\mathrm{O}$ mesmo ocorreu com o tratamento $\mathrm{T}_{5}$, na idade de 56 dias, em relação aos 28 dias. Tal comportamento pode ser explicado pelas variações ambientais de 
temperatura e umidade relativa do ar ocorridas durante o processo de armazenagem dos tijolos. Entretanto, no geral, o maior período de cura (182 dias) foi o que proporcionou as maiores médias em valores absolutos de resistência à compressão simples. Esse aumento de resistência mecânica ocorrido nas misturas de solo-cimento-resíduo indica a formação, ao longo do tempo, de compostos cimentantes que melhoram as propriedades mecânicas da mistura (MILANI \& FREIRE, 2006). Acredita-se que o efeito de estabilização do solo com cimento foi mais significativo do que a influência negativa do resíduo ao sistema solo-cimento.

Em se tratando da capacidade de absorção de água, os tratamentos $T_{1}$ e $T_{6}$ diferenciaram-se estatisticamente do tratamento $T_{9}$, mas não das demais combinações. Os coeficientes de variação obtidos no ensaio de absorção de água foram elevados, fato não raro em se tratando de material acrescido de biomassa vegetal e devido, também, à metodologia do ensaio descrita no item Material e Métodos. Ao serem secos em estufa e em seguida levados à saturação em água, a estrutura dos tijolos, e em especial daqueles moldados com incorporação de biomassa vegetal, sofre fissurações internas que podem causar comportamentos distintos entre as repetições analisadas. Entretanto, cumpre salientar que todos os tratamentos se mantiveram abaixo dos $20 \%$ de absorção total de água exigidos pela NBR 8491.

Conforme a Tabela 4 e ilustrado na Figura 4, o menor valor de capacidade de absorção de água foi no tratamento $\mathrm{T}_{1}(0 \%$ de resíduos), o que era de se esperar devido à maior quantidade de cimento e ausência de resíduos vegetais (que conferem maior massa específica aparente ao solo e menor volume de poros). Os valores mais elevados da absorção ocorreram nos tratamentos $\mathrm{T}_{5}$ e $\mathrm{T}_{9}$ devido à presença de maior quantidade de resíduo vegetal $(40 \%$ de substituição do cimento, pelo resíduo vegetal).

Nas Figuras 6 e 7, apresentam-se, respectivamente, para os tijolos de solo-cimento-casca de arroz e solo-cimento-casca de braquiária, os diagramas tensão-deformação obtidos durante os ensaios de compressão simples na idade de 7 dias.

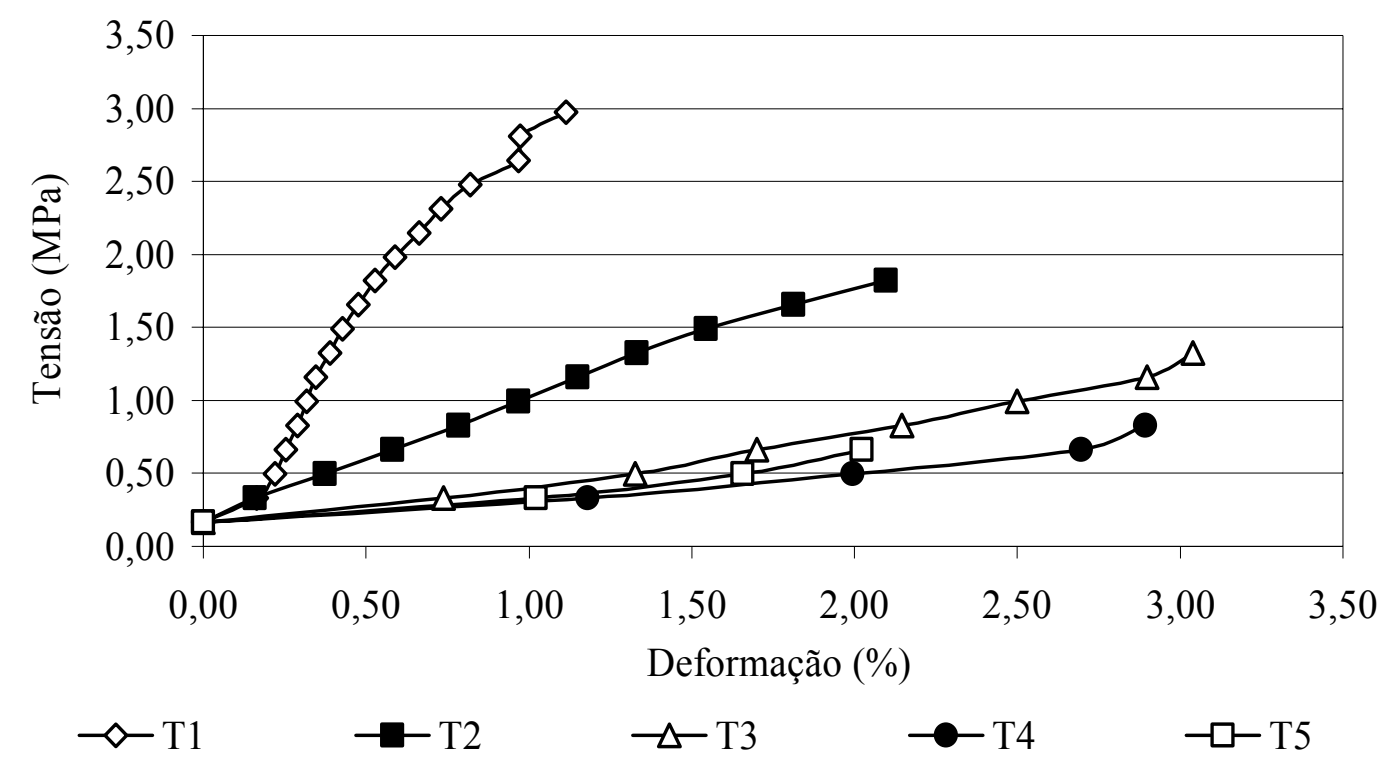

FIGURA 6. Diagrama tensão-deformação dos tijolos de solo-cimento-casca de arroz, na idade de 7 dias, em comparação à testemunha $T_{1}$. Tension-deformation diagram of the soilcement bricks with rice husk at the 7 days in comparison to $\mathbf{T}_{1}$. 


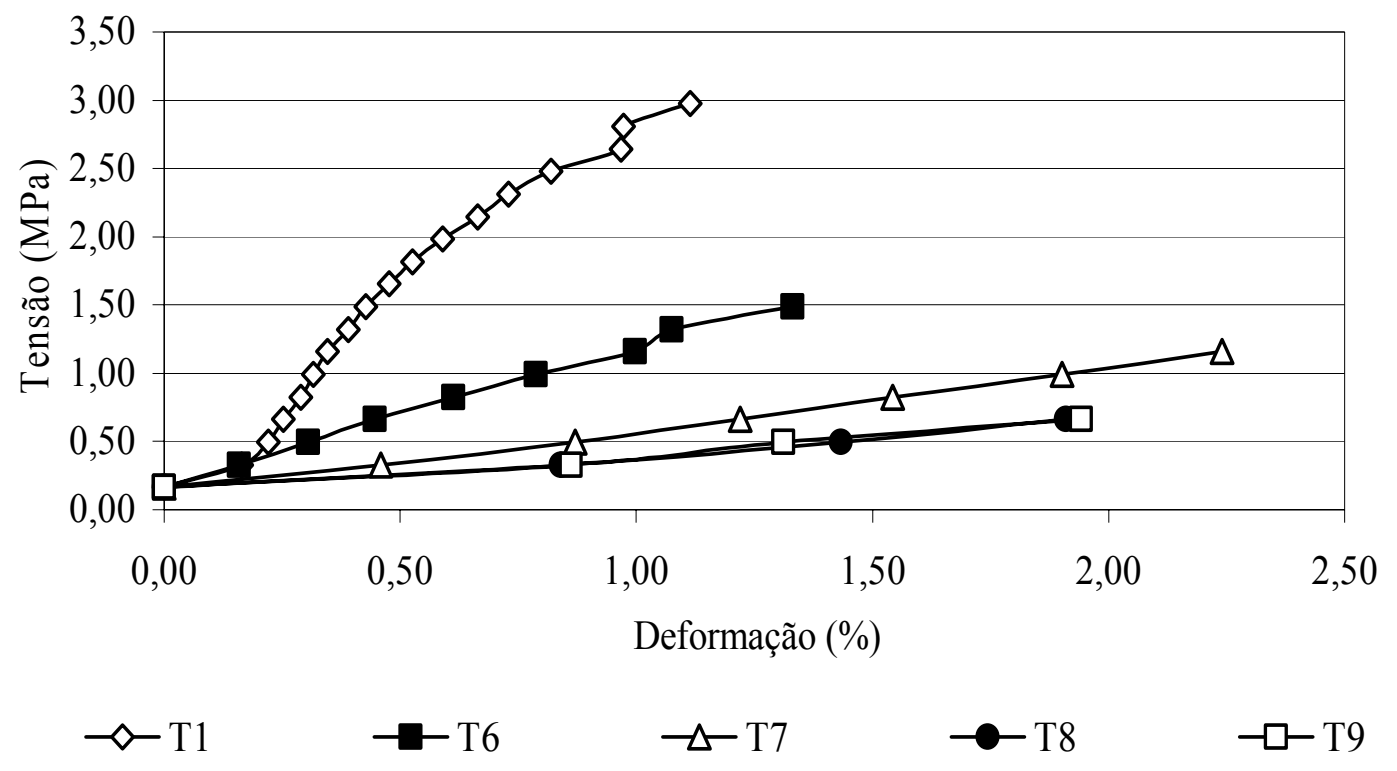

FIGURA 7. Diagrama tensão-deformação dos tijolos de solo-cimento-casca de braquiária, na idade de 7 dias, em comparação à testemunha $T_{1}$. Tension-deformation diagram of the soilcement bricks with brachiaria husk at the 7 days in comparison to $T_{1}$.

Pelas Figuras 6 e 7, verifica-se que, à medida que se aumentaram os teores de cascas, para ambos os resíduos, houve decréscimo na tensão, enquanto as deformações, no geral, tenderam a aumentar significativamente com o aumento dos teores de casca. Esse comportamento, num primeiro momento, pode ser uma característica indesejável caso se preconize maior resistência mecânica. Por outro lado, partindo-se da premissa de que é desejável que os materiais apresentem deformabilidade, característica essa relacionada a sua capacidade de absorção dos esforços mecânicos, a presença de fibras vegetais pode ser benéfica no controle das fissurações causadas pelos esforços mecânicos, conforme considerações de AGOPYAN et al. (2005).

De acordo com KHEDARI et al. (2005), outro aspecto benéfico da presença de fibras em materiais baseados em terra crua, desde que o seu comportamento mecânico não seja comprometido, é a obtenção de um produto de menor condutividade térmica, promovendo, assim, a redução da transferência de calor e menor consumo energético para o controle da temperatura interna das edificações.

\section{CONCLUSÕES}

Apesar dos altos valores de coeficientes de variação observados, todos os tratamentos apresentaram baixa capacidade total de absorção de água,' mantendo-se dentro das normas.

A adição da casca de arroz proporcionou valores de resistência à compressão simples mais elevados do que aqueles proporcionados pela casca de braquiária, nos teores correspondentes, em todas as idades de cura.

Adotando-se 1,5 MPa como valor mínimo de resistência à compressão simples aos 7 dias, a substituição parcial do teor de cimento por resíduo poderá ser realizada nos tratamentos com $10 \%$ casca de arroz e braquiária, respectivamente.

Cumpre salientar que, para fins de recomendação prática, outros testes mecânicos deverão ser realizados, como, por exemplo, o da compressão diametral, de modo a verificar o provável aumento de resistência à tração proporcionado pelos resíduos. 


\section{REFERÊNCIAS}

ABNT. ASSOCIAÇÃO BRASILEIRA DE NORMAS TÉCNICAS. NBR 7181. Solo. Análise granulométrica. Rio de Janeiro, 1984. 13 p.

. NBR 8491. Tijolo maciço de solo-cimento. Rio de Janeiro, 1992a. 8 p.

. NBR 8492. Tijolo maciço de solo-cimento. Determinação da resistência à compressão e absorção de água. Rio de Janeiro, 1992b. 8 p.

. NBR 10832. Fabricação de tijolo maciço de solo-cimento com a utilização de prensa manual. Rio de Janeiro, 1989. 3 p.

. NBR 11578. Cimento Portland CPII-F-32. Rio de Janeiro, 1991. 5 p.

AGOPYAN, V.; SAVASTANO JÚNIOR, H.; JOHN, V.M.; CINCOTTO, M.A. Developments on vegetable fibre-cement based materials in São Paulo, Brazil: an overview. Cement \& Concrete Composites, Kidlington, v.27, n.5, p.527-36, 2005.

AKASAKI, J.L.; SILVA, A.P. Estudo de composições do solo estabilizado com cal e resíduos agroindustriais. In: CONGRESSO BRASILEIRO DE ENGENHARIA AGRÍCOLA, 30., 2001, Foz do Iguaçu. Anais... Foz do Iguaçu: SBEA, 2001. 1 CD-ROM.

BERALDO, A.L.; TOJAL, J.H.V. Termorregulação de equinos em uma cocheira feita com blocos vazados de argamassa de cimento, areia e casca de arroz. Engenharia Rural, Piracicaba, v.13, n.1, p.21-30, 2002.

FERREIRA, R. de C. Desempenho físico-mecânico e propriedades termofísicas de tijolos e minipainéis de terra crua tratada com aditivos químicos. Tese (Doutorado em Construções Rurais e Ambiência) - Faculdade de Engenharia Agrícola, Universidade Estadual de Campinas, Campinas, 2003.

FERREIRA, R. de C.; FREIRE, W.J. Propriedades físico-mecânicas de solos estabilizados com cimento e silicato de sódio avaliadas por meio de testes destrutivos e não-destrutivos. Engenharia Agrícola, Jaboticabal, v.23, n.2, p.221-32, 2003.

FERREIRA, R. de C.; OLIVEIRA, M.F. Incorporação de resíduos vegetais e seus efeitos sobre o desempenho físico-mecânico de solo-cimento. In: CONGRESO LATINO-AMERICANO Y DEL CARIBE DE INGENIERÍA AGRÍCOLA, 7., 2006, Chillán. Proceedings ... Ciudad del México: ALIA, 2006. 1 CD-ROM.

FREIRE, W.J. Materiais alternativos de construções. In: FREIRE, W.J.; BERALDO, A.L. (Coords). Tecnologias e materiais alternativos de construção. Campinas: Ed. Unicamp, 2003. p.27-54.

HOUBEN, H.; GUILLAUD, H. Earth construction: a compressive guide. London: Intermediate Technology Publications, 1994. 362 p.

KHEDARI, J.; WATSNASATHAOIRN, P.; HIRUNLABH, J. Development of fibre-based soil cement block with low thermal conductivity. Cement \& Concrete Composites, Kidlington, v.27, n.1, p.111-16, 2005.

MESA-VALENCIANO, M.C.; FREIRE, W.J. Características físicas e mecânicas de misturas de solo, cimento e cinzas de bagaço de cana-de-açúcar. Engenharia Agrícola, Jaboticabal, v.24, n.3, p.484-92, 2004.

MILANI, A.P. da S.; FREIRE, W.J. Características físicas e mecânicas de misturas de solo, cimento e casca de arroz. Engenharia Agrícola, Jaboticabal, v.26, n.1, p.1-10, 2006. 